\title{
An Empirical Investigation into Physician Preferences in Drug Prescription: An Integrated Methodology of AHP and QFD
}

\author{
Farzana Elahi $^{1}$, Shamsad Ahmed ${ }^{1}$, Mahbubul Haque ${ }^{1} \&$ Nazreen Chowdhury $^{1}$ \\ ${ }^{1}$ Department of Business Administration, University of Asia Pacific, Dhaka 1215, Bangladesh \\ Correspondence: Mahbubul Haque, Department of Business Administration, University of Asia Pacific, Dhaka \\ 1215, Bangladesh. E-mail: mahbubhasin@gmail.com
}

Received: August 11, 2016

Accepted: September 2, $2016 \quad$ Online Published: September 22, 2016

doi:10.5539/ijms.v8n5p81

URL: http://dx.doi.org/10.5539/ijms.v8n5p81

\begin{abstract}
In order to sustain in a competitive market like pharmaceutical in Bangladesh, it is important to get an insight into physicians' preferences in prescribing the drugs. The aim of this work is to investigate and address the physician requirements through an integrated methodology of Analytic Hierarchy Process (AHP) and Quality Function Deployment (QFD). In this research, an expert panel has been interviewed to recognize the criteria affecting physicians' decisions. The results from AHP derived through Expert Choice software demonstrate that from the viewpoint of physicians, out of the five criteria, quality of product offering is ranked highest in prescribing the drugs followed by the reputation of the company, relationship enjoyed with the company, etc. As for the technical aspects, derived from the relationship matrix of AHP and QFD, out of the sixteen, brand image is ranked first followed by the quality of raw and packaging materials, skilled production personnel etc. The contribution of this research is expected to enable the managers in the pharmaceutical companies to recognize the factors that influence physicians in prescribing drugs for the patients and help them find out challenging items with preeminent alternatives. Few suggestions for future research are also put forward.
\end{abstract}

Keywords: pharmaceutical industry, physician preferences, Analytical Hierarchy Process (AHP), Quality Function Deployment (QFD)

\section{Introduction}

The innovation of the pharmaceutical drugs has brought a revolution in the lives of human beings. The primary goal of these drugs is to make them immune to the curse of the diseases, or help them recover from illnesses. However, these pharmaceuticals would be as effective as these are intended to be only if they are manufactured in the proper environment, free from any germs, and applied with the right proportions (Siddiqui et al., 2013). Despite the voice of the patients or the consumers getting more pronounced by the day, the drug purchasing activity generally runs along the physician-pharmacist-patient continuum with the physicians being at the center of the process (Merino-Castello, 2003). Due to the changing trends in pharmaceutical companies, producers are looking for innovative ways to make a distinction of their products. In most cases, physicians have played the role of influencers and decision makers in pharmaceutical industry. According to BMA (2010), physicians are responsible to guide and counsel on the development of new pharmaceutical products, and are concerned in reviewing and communicating data arising from complaints made about the products. Pharmaceutical marketing aimed at physicians is becoming a source of information on prices of some drugs, in sharp contrast to pharmaceutical marketing of the past (Ellison et al., 1997). Pharmaceutical companies thus need to focus on physicians' requirements of actual data to control total cost of care by branding drugs (Wyman, 2016). As the physicians play an important role in pharmaceutical industries, we desired to observe what factors they take into account in prescribing the drugs, and what technical aspects the companies are required to take in order to meet the considerations of the physicians.

The pharmaceutical industry of Bangladesh is one of the fastest growing sectors of the country with its domestic market valued at about \$1.14 billion, according to IMS Health Bangladesh, as cited in Haroon (2012). In 1982, Bangladesh formulated its National Drug Policy and the Drugs Control Ordinance in order to ensure accessibility, affordability and safety of essential drugs (da Cunha, 2007). The Drugs Control ordinance limits the production and sale of certain types of drugs as well as the marketing rights of foreign companies in the market. Besides, the MNCs having no manufacturing facility on their own in Bangladesh are not permitted to market their products. 
This has resulted in a significant withdrawal of foreign companies from the domestic market and the subsequent robust local production. This is evident in the fact that of the total pharmaceuticals market in Bangladesh, the local companies generate a market share hovering around $87 \%$, while the multinational companies (MNCs) account for around $10 \%$ with the rest being imported (Chowdhury, 2010). More than $95 \%$ of the total demand of Bangladesh is currently met by domestic manufacturing (Shamaly \& Saha, 2009); the rest mainly constitutes of very specialized products like vaccines, anti-cancer products, etc.

The current study is aimed at, first, ascertaining the priority of the important factors that doctors in Bangladesh consider while prescribing the drugs. Once identified, the second objective pertains to the technical dimensions that companies need to prioritize in addressing the doctors' considerations. Analytic hierarchy Process (AHP) is applied to rank the priorities to meet the first objective; for the second, Quality Function Deployment (QFD) is employed to figure out the weights of the technical measurements. We believe the application of this integrated methodology of AHP and QFD would offer an insight into the factors influencing doctors' preferences as well as the dimensions the drug companies need to address in meeting those preferences.

This paper is structured as follows: in section two, a literature review of the application of AHP and QFD in various areas is discussed. In Section 3, we introduce the model of demand and theoretical basis of AHP and QFD are analyzed. The empirical implementation of the model and estimation techniques and the findings are discussed in Section 4. We conclude in Section 5 with suggestion of future research.

\section{Literature Review}

This section highlights the literature review conducted in different areas taking into account the application of both AHP and QFD. These are presented below:

Alinezad et al. (2013) conducted a study on supplier selection and evaluation in a pharmaceutical company using an integrated methodology of Fuzzy AHP (FAHP) and QFD. For this, the authors first identified customer requirements considering three aspects: technical (technical information, technical service, capacity of R\&D, and supplier certificate), commercial (financial capacity, financial offer, discount, and quantity discount), strategic (organization's culture and strategy, industry's situation and reputation, performance history, suppliers' information system, and transportation). The analysis of FAHP indicated that technical information possesses the highest importance followed by service and supplier certificate. Other aspects that feature prominently include industry's reputation, financial offer and capacity of R\&D. Once these customer requirements were categorized, the authors assessed the candidate suppliers based on four criteria, namely, cost, quality, supplier standing and delivery time. The combined methodology of FAHP and QFD assisted the authors in ranking the suppliers that would ensure the realization of the business objectives as well as significantly satisfying the customers' needs.

Tendayi \& Fourie (2013) employed combined AHP-QFD approach in evaluating the importance of a set of Maintenance Excellence (ME) criteria in the railway environment and identified possible lean tools to meet those criteria. Maintenance organization set fourteen maintenance criteria which are ranked in terms of their importance to achieve the objectives. These criteria are-spare parts and material availability, use of FMMS/SAP, key performance indicators, maintenance contracting, maintenance organization \& structure, policy and strategy, continuous improvement efforts, workforce involvement, conformance quality, comprehensive work orders, management support, personnel skills training, detailed operating procedures, schedule compliance. Once these maintenance criteria are categorized, the researchers indentified nine lean tools to address these criteria. These tools namely are: Balanced Scorecard, Visual Management, 5S, Kaizen, Standardization, Hoshin, Just in Time, Kanban, Poka-Yoke. The combined AHP and QFD helped the researchers in positioning the lean tools that would ensure maintenance standards in a way that eliminates waste and at the same time adds value.

Felice \& Petrillo (2010) proposed a new methodological approach to state customer needs and functional characteristics of the filter in ceramic material production through the employment of an integrated QFD-AHP model. The authors assumed that in order to be competitive in terms of price and performance, customers' needs should be defined during the planning phase. In this regard, the authors determined that the most popular criterion to purchase the product of the firm is filtering power, followed by lifetime, capacity of regulating the flow, product certification, dimensional specification of coupling, and competitive price. Later they focused on functional characteristics, namely, certification, mechanical and thermal resistance, dimension, filtering degree, and cost of raw materials. Analysis of the result demonstrated that QFD-AHP rank the relative importance of the weight of the customers' requests by putting them into quality measurable characteristics, as well as judging the rationality, productivity and adequacy to the market.

Jain \& Singh (2014) applied QFD-AHP multi-criteria group decision making approach for the strategic supplier selection in a medium scale industry producing TMT bars. From the company's requirements the authors 
obtained four criteria for selecting suppliers, namely, quality, delivery, performance history, and cost. However, according to supplier consideration experience, technical capability, quality system certification, geographical position, and raw material procurement were chosen as criteria. AHP was applied to generate the overall score for alternative suppliers and from the scores it was revealed that technical capability and quality system certification are the major criteria followed by experience.

In their research, Rajesh \& Malliga (2013) combined Analytic Hierarchy Process (AHP) and Quality Function Deployment (QFD) to addresses the relationship among the criteria for supplier selection decision making. According to their findings, due to globalization of trade and internet facilities customer preferences have changed with certain requirements. House of Quality (HOQ) was used to select supplier in order to meet certain requirements that the company has established and then tried to identify which of the suppliers' attributes (external variables) have the greatest impact on the achievement of its established objectives.

Buyukozkan et al. (2007) came out with a new fuzzy group decision making approach to respond customer demands in product development. On the other hand, Lee et al. (2008) referred to an integrated approach by integrating Kano model with fuzzy mode into the QFD matrix and adjusting customer requirements weights. Olhager \& West (2002) used QFD methodology in an attempt to build a structured method to deploy flexibility-related customer requirements in the features of various manufacturing systems.

Tasneem et al. (2014) looked into a hybrid model of SERVQUAL, AHP, and QFD matrix to increase awareness of customer needs in telecom industry. In another study, Gharakhani \& Eslami (2012) used QFD to amend service quality according to customers' needs and identified the variables such as offering qualified food, existence of sauna and swimming pool, friendly behavior and attitude of personnel and their proper appearance those are affecting customer satisfaction.

To our knowledge, no such study with the application of this combined methodology has been conducted in the pharmaceutical industry of Bangladesh. Thus, it will fill the void of the extant literature, particularly regarding this arena of paramount health concern to the human lives, taking into consideration of the integrated methodology of both AHP and QFD.

\section{Methodology}

This section highlights the two methods, namely, AHP and QFD, applied in this study. First, a brief discussion of AHP with its pair-wise comparison scale is presented. This is followed by highlighting the QFD procedures that includes house of quality and the symbols used in determining the relationship between the factors affecting customer choices or requirements of pharmaceutical products and the technical aspects needed to satisfy those requirements.

\subsection{Analytic Hierarchy Process (AHP)}

Developed by Saaty (1980), the AHP is a widely used framework for multi-criteria decision making purposes (Vaidya \& Kumar, 2006). It comprises three steps: first, it decomposes the unstructured problem into a hierarchy of different levels of elements; second, it determines relative worth/priorities of the factors through pair-wise comparison scale; third, it synthesizes the priorities to realize the ultimate goal of the problem at hand. Thus, in this study, at the top of the hierarchy lies the main goal i.e., ascertaining the factors affecting a doctor's choice of pharmaceutical products; and, the second level of the hierarchy represents the factors, namely, quality of products, availability of products, reputation of the company, relationship with the company and price of the product. The elements in the AHP hierarchy for the present study and the pair-wise comparison scale are displayed in Figure 1 and Table 1, as shown below:

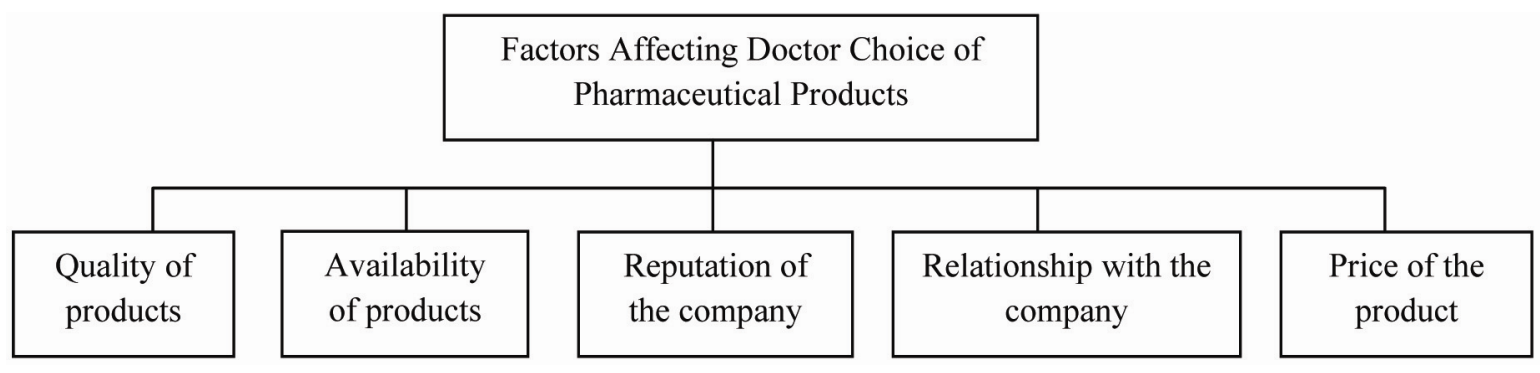

Figure 1. AHP hierarchy process 
Table 1. Pair-wise comparison scale for AHP preferences

\begin{tabular}{ll}
\hline Numerical rating & Verbal Judgments of Preferences \\
\hline 9 & Extremely preferred \\
7 & Very strongly preferred \\
5 & Strongly preferred \\
3 & Moderately preferred \\
1 & Equally preferred \\
$2,4,6,8$ & Ratings in between \\
\hline
\end{tabular}

\subsection{Quality Function Deployment (QFD)}

QFD is a graphical analysis tool that portrays customer (in this study, customers are the physicians) wants or requirements and the technical aspects required to satisfy these requirements (Bossert, 1991; Sanford, 2005). In QFD terminologies, customer wants and technical aspects are respectively known as 'WHAT's and 'HOW's. The tool utilizes a diagram known as House of Quality (HOQ), as shown in Figure 2. As observed, the left side of the HOQ refers to the doctor choices; in this paper, the rankings of these choices are obtained applying AHP; a number of technical/design characteristics are then identified and placed at the top of HOQ. Once these are identified, the next step is to derive the relationship matrix between the two. In developing the matrix, it is important to note that one single customer requirement may be related to more than one technical requirement, or vice versa. If any technical feature is not related with the customer requirement, the respective cell in the relationship matrix is kept blank (Islam et al., 2007). Usually, three symbols are used to represent the relationships as shown in Table 2.

Table 2. Symbols used in HOQ

\begin{tabular}{lll}
\hline & Meaning & Weight \\
\hline$\bullet$ & Strong Relationship & 9 \\
$\mathrm{O}$ & Medium Relationship & 3 \\
$\nabla$ & Weak Relationship & 1 \\
\hline
\end{tabular}

Once all the possible relationships between every pair of customer and technical requirements are identified, the weights of all the technical requirements are calculated and prioritized. This is done by multiplying the weights in the relationship matrix by the rankings of the doctor choices (as derived by AHP in this paper).

\begin{tabular}{|c|c|}
\hline \multirow{2}{*}{$\begin{array}{c}\text { Customer Requirements } \\
\text { (WHATs) }\end{array}$} & Technical/Design Requirements (HOWs) \\
\cline { 2 - 2 } & Relationship Matrix (Between WHATs and HOWs) \\
\hline & Priorities of Technical Requirements \\
\hline
\end{tabular}

Figure 2. House of quality

\subsection{Data Collection and Data Analysis}

After proper investigation, when the disease has been identified, a doctor decides about appropriate medication. First s/he takes the decision about the generic. Then s/he selects the company and brand. Depth interview of one renowned professor of medicine and two professionals of pharmaceutical marketing (one of whom is Marketing Director and the other General Manager of renowned pharmaceutical companies of Bangladesh) were taken to establish customers' (in this case doctors') requirements; later on, these factors were analyzed using Analytic Hierarchy Process (AHP) to establish their priorities. The factors are as follow: availability of products; reputation of company; quality of product; relationship of the doctor with the company; price of the product.

Data analysis for AHP is carried out by Expert Choice software version 11.0. It is to be noted that the inconsistency that might arise out of the subjective preferences in applying AHP should not be more than 0.10 . Once the weights of the five factors are obtained, these are placed into the House of Quality of QFD framework to ascertain the priorities of technical requirements required to address the doctor choice regarding pharmaceutical products. 


\section{Findings of the Study}

This section presents the findings and their discussions of both AHP and QFD techniques. First, using pair-wise comparison procedure in AHP, the questionnaires as shown in Table 2 are completed. The weights or the rankings of the five factors are then generated by Expert Choice software. As shown in Figure 3, the highest priority is attributed to the quality of products $(0.487)$, followed by reputation of the company (0.23), relationship with the company $(0.15)$, availability of product $(0.076)$, and price of product $(0.057)$. As revealed by the synthesis output, the value of the overall inconsistency is 0.06 , which is lower than the threshold value of less than 0.10 , thus demonstrating the reliability of the result.

\section{Model Name: DOCTOR PERSPECTIVE}

Priorities with respect to:

Goal: Criteria Affecting Doctor's Choice

Availability of the Product
Reputation of the Company
Quality of the Product
Relationship with the Company
Price of the Product
Inconsistency $=0.06$
with 0 missing judgments.

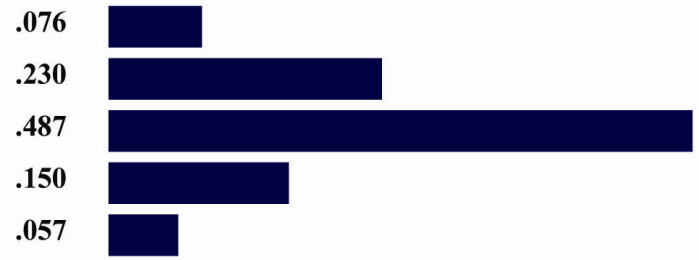

Figure 3. Ranking of the factors affecting customer choice as generated by Expert Choice

The relative weights of the above mentioned five factors are then incorporated in the left side of the House of Quality (HOQ) in QFD procedure (Table 3). As can be observed, sixteen technical characteristics are identified by taking depth interview of marketing director of one reputed multinational pharmaceutical company and general manager (marketing) of the leader of the industry. Sixteen most important factors are: Quality of Raw Materials (QRM); Skilled Production Personnel (SPP); Storage Facility (StF); Brand Image (BI); CSR Activity (CSR); Company Support towards Doctors (CSD); Affordability of Patient (AP); Production Capacity (PC); Sales Forecast (SF); Management Attitude towards Ethical Practices (MEP); Enough Sales force (ES); Quality of Medical Representatives (QR); Patients' Opinion (PO); Product Packaging (PrP); Frequency of Visit by Representatives (FVR); Competitors' Price (CP). Cross relationship among doctor choices and technical requirements have been identified using $\mathrm{QFD}$.

Table 3. Prioritization of technical aspects through QFD analysis

\begin{tabular}{|c|c|c|c|c|c|c|c|c|c|c|c|c|c|c|c|c|}
\hline & QRM & SPP & $\mathrm{StF}$ & $\mathrm{BI}$ & CSR & CSD & $\mathrm{AoP}$ & $\mathrm{PC}$ & SF & MEP & ES & $\mathrm{QR}$ & $\mathrm{PO}$ & $\operatorname{PrP}$ & FVR & $\mathrm{CP}$ \\
\hline $\begin{array}{l}\mathrm{AP} \\
(0.072)\end{array}$ & & $\mathrm{O}$ & $\bullet$ & $\nabla$ & & & & • & $\mathrm{O}$ & $\nabla$ & • & $\bullet$ & $\mathrm{O}$ & $\mathrm{O}$ & $\nabla$ & \\
\hline $\begin{array}{l}\mathrm{RC} \\
(0.202)\end{array}$ & $\bullet$ & $\mathrm{O}$ & $\mathrm{O}$ & $\bullet$ & $\bullet$ & $\mathrm{O}$ & & & & $\nabla$ & $\mathrm{O}$ & $\bullet$ & $\mathrm{O}$ & $\mathrm{O}$ & $\mathrm{O}$ & $\nabla$ \\
\hline $\begin{array}{l}\text { QP } \\
(0.532)\end{array}$ & $\bullet$ & $\bullet$ & $\mathrm{O}$ & $\bullet$ & & & & $\nabla$ & & $\mathrm{O}$ & & & $\mathrm{O}$ & $\nabla$ & & \\
\hline $\begin{array}{l}\mathrm{RwC} \\
(0.141)\end{array}$ & $\nabla$ & & & $\mathrm{O}$ & $\mathrm{O}$ & • & $\nabla$ & & & & $\mathrm{O}$ & • & $\mathrm{O}$ & $\nabla$ & $\bullet$ & \\
\hline $\begin{array}{l}\text { PP } \\
(0.054)\end{array}$ & $\bullet$ & $\mathrm{O}$ & $\mathrm{O}$ & $\mathrm{O}$ & $\nabla$ & $\nabla$ & $\bullet$ & $\nabla$ & & $\nabla$ & & & & $\mathrm{O}$ & & $\bullet$ \\
\hline Technica & 7.23 & 5.77 & 3.01 & 7.26 & 2.30 & 1.93 & 0.63 & 1.23 & 0.22 & 1.92 & 1.68 & 3.74 & 2.84 & 1.66 & 1.95 & 0.69 \\
\hline 1 Weight & 2nd & $3 \mathrm{rd}$ & 5 th & $1 \mathrm{st}$ & 7th & 9th & 15 th & 13th & 16th & 10th & 11th & 4th & 6th & 12 th & 8th & 14th \\
\hline $\begin{array}{l}\text { Total } \\
\text { Weight }\end{array}$ & $=7.23$ & $.77+3$ & $-7.26+$ & +1.93 & $63+1.2$ & $0.22+$ & +1.68 & $74+2.8$ & $1.66+1$ & $+0.69=$ & 4.06 & & & & & \\
\hline $\begin{array}{l}\text { Relative } \\
\text { Weight } \\
(\%)\end{array}$ & 16.41 & 13.1 & 6.84 & 16.48 & 5.21 & 4.38 & 1.42 & 2.8 & .49 & 4.37 & 3.81 & 8.48 & 6.45 & 3.76 & 4.42 & 1.56 \\
\hline
\end{tabular}


For further clarification, as Availability of Product (AP) and Storage Facility (StF) are strongly related, the weight 9 has been used in the corresponding cell. Similarly, as Quality of Product (QP) has medium relationship with Management Attitude towards Ethical Practices (MAEP), 3 has been given in the corresponding cell. The values of total weight are calculated by multiplying the weights or rankings of the factors (doctors' requirements) derived by AHP with the symbols $\bullet, \mathrm{O}$ and $\nabla$ (having numerical values of 9,3 and 1 , respectively) in the relationship matrix. For example, total weight of quality of raw materials (QRM) is obtained as follows: $0.202 * 9$ $+0.532 * 9+0.141 * 1+0.054 * 9=7.23$, the total weight for the first column in the table. Similarly, weights of other technical requirements have been calculated. The ranking of weights has also been shown. Finally, the relative weights (priorities in \%) are measured by dividing the individual weight of each technical requirement by the total weight. Once again, calculation to find out relative weight of Quality of Raw Materials (QRM) has also been shown in the House of Quality, which is $16.41 \%$ [7.23*100/44.06], the second highest relative weight.

\section{Discussion \& Managerial Implications}

This section discusses the study findings and their implications for the companies. First, priority-wise description of the factors affecting doctors' choice as obtained by AHP is given as follows:

Quality of the Product (QP): Pharmaceutical products are used to treat a diseased person, to save life. Thus it is only natural that a doctor will not prescribe a substandard product. To judge the quality, the doctor prescribes the medicine to a patient, and then $\mathrm{s} / \mathrm{he}$ monitors the result. If the result is not positive, s/he considers it as substandard and will not prescribe in future. If $\mathrm{s} / \mathrm{he}$ prescribes that product, the medicine will not cure the disease, which will make the patient dissatisfied leading to negative word of mouth. His/her professional reputation will be jeopardized. As a result, it is not surprising that quality of product has obtained more than $50 \%$ relative weight.

Reputation of the Company (RC): It has got the second highest relative importance, $20.2 \%$. Consumers now-a-days are becoming more educated, more conscious about brands. If the patient or his/her attendant observes that the doctor has prescribed medicine of an unknown company, s/he becomes skeptical. To avoid this situation, especially if the patient is educated, doctors normally avoid prescribing medicines of companies which are not reputed.

Relationship of Doctor with the Company (RwC): This comes as the third highest important factor with $14.1 \%$ relative importance. Relationship normally depends on the professional support the companies offer to the doctors, e.g., to purchase medical instrument or to attend foreign medical seminar/symposia. If a doctor finds that he has two options, two same quality brands from two reputed companies for the treatment of a disease, s/he will choose the company with which s/he has a good relationship.

Availability of the Product (AP): When a doctor prescribes a medicine, s/he thinks whether the product will be available in the surrounding drug stores or not. If the patient does not get the medicine, s/he will become dissatisfied and will come back to the doctor to get a new name. This is frustrating both for the doctor and the patient. The factor has got $7.2 \%$ importance.

Price of the Product (PP): Especially if the patient is not affluent, the doctor will consider the price. If the product is expensive, s/he will not prescribe it. This factor is in fifth position with $5.4 \%$ relative importance.

Now, a discussion on top five technical requirements is done below:

Brand Image (BI): This requirement has got the highest importance with 7.26 weight and a relative weight of $16.48 \%$. It has strong correlation with reputation of the company (RC) and quality of the product (QP) and moderate correlation with relationship of doctor with the company $(\mathrm{RwC})$ and price of the product $(\mathrm{PP})$. It indicates that the consumers of pharmaceutical market of Bangladesh have become highly brand conscious. Focusing on this technical factor thus deserves utmost attention during strategy development.

Quality of Raw and Packaging Materials (QRPM): This is the second most important technical criterion which has strong correlation with reputation of the company (RC), quality of the product (QP) and price of the product (PP) and a weak correlation with relationship of doctor with the company (RwC). The weight is 7.23 and relative weight is $16.41 \%$. Although it is the second most important technical criterion, weight is very close to the most important one. So it is mandatory for pharmaceutical companies of Bangladesh to use high quality raw and packaging materials to ensure production of quality products which will create a positive impact on prescription share leading to increased sales.

Skilled Production Personnel (SPP): It has a strong correlation with quality of the product (QP) and moderate correlation with availability of the product (AP), reputation of the company (RC) and price of the product (PP) resulting into a weight of 5.77 with $13.1 \%$ relative weight. It is obvious that if the company does not have 
skilled production personnel, it cannot produce quality product at the right time to make it available which will damage the reputation of the company. Possibility of wastage during manufacturing will also go up leading to increased cost which will create a negative impact on price. Proper selection and necessary training of production personnel are, therefore, mandatory for company success in this industry.

Quality of Medical Representatives (QR): This is the fourth important factor with a weight of 3.735 and relative weight of $8.48 \%$. It has a strong correlation with availability of the product (AP), reputation of the company (RC) and relationship of doctor with the company (RwC). It is a well established phenomenon that in pharmaceutical product marketing, doctors are treated as customers. If they prescribe, only then a product will be sold. This customer group is highly educated. They do not prescribe a product until they are satisfied. So, the personnel who will represent the company and its products, should be educated, and have perfect product knowledge; they should be properly groomed in terms of dress up, behavior and etiquette. If the representative has all of the above mentioned attributes, s/he will become confident. This confidence is crucial to convince a doctor.

Storage Facility (StF): This technical requirement has a strong correlation with availability of product (AP) and moderate correlation with reputation of the company (RC), quality of product (QP) and price of the product (PP). The weight is 3.012 and relative weight is $6.84 \%$. Enough storage space (warehouse / depot) with modern facilities to ensure proper preservation of raw materials and finished products at factory and in different parts of the country will have to be ensured.

A brief description of other technical requirements presented in the House of Quality table has been given below. The companies those belong to pharmaceutical industry of Bangladesh should put emphasis on these requirements as well.

Patients' Opinion (PO), Affordability of Patient (AoP), Competitors' Price (CP) and Product Packaging (PrP): The opinion of the patients creates a positive or negative impact on the doctor whenever a patient who is under his / her treatment appreciates positive action of a medicine or raises complaints against it, respectively. Depending on the affordability of the patient, doctors need to select an expensive or low cost option. As to the competitors' price, it has a strong relationship with the price of the product (PP); a company should always monitor its competitors' list price (TP), discounts, and allowances, credit policies at wholesale and retail level. These apart, an attractive packing always creates a positive psychological effect on the patient which helps in recovery. Doctors and retail pharmacists are also interested to prescribe keep or sell a product with attractive packaging.

Frequency of Visit by Representatives (FVR) and Company Support towards Doctors (CSD): Both the requirements have strong correlation with relationship of doctor with the company (RwC). Without support of the doctors, surviving in this industry is totally impossible. So, extra care should be given to address these two requirements. Supports could be given in categories like buying instruments required for this profession or attending a foreign seminar / symposia, which are ethical. Companies should avoid giving support in unethical maters to mitigate pollution of the environment of the industry.

Management Attitude towards Ethical Practices (MAEP) and CSR Activity (CSR): In this industry, this is a vital requirement. If the attitude is not positive, it can lead to production of substandard medicines. These medicines will not cure; in contrast it may kill life. Sometimes demand for a medicine increases manifold when a disease becomes epidemic or endemic. At that time, to satisfy the increased demand, a company may skip some steps like in process quality control to produce the medicine in short time. Ensuring the quality is not possible in this situation even if the company has skilled production personnel, quality raw materials and high-tech machineries. Regarding CSR activity, it has a strong correlation with reputation of the company (RC); thus, the company should have commitment in various social issues.

Sales Forecast (SF), Production Capacity (PC) and Enough Sales force (ES): Sales forecast should be done properly. Depending on this, production quantity will depend, so will be the availability of product (AP). However, this availability can be ensured when the company will have sufficient number of sales personnel to cover the total country.

\section{Conclusion}

In today's intensely competitive globalised markets, companies are constantly under pressure to find ways to identify customer needs and satisfy them. As a result, they are forced to respond quickly and accurately to the needs and satisfaction of the customers, and establish their positions in the market. In this regard, the current study tried to examine the factors influencing customer (in this case, doctor) decision making in 
prescribing/choosing pharmaceutical products. This paper used a combined AHP and QFD approach to develop an effective decision-making method. In this approach, AHP is used to determine the rankings of the criteria, whereas QFD is used to prioritize the technical requirements that would satisfy the criteria as prescribed by the doctors. Five criteria have been used in conducting this research, namely, quality of products, availability of products, reputation of the company, relationship with the company, and price of the product. In doing so, AHP is employed as it quantifies the qualitative factors with a scale called Saaty's 9-point scale. For this purpose, Expert Choice software version 11.0 is used. The result indicates that quality of product criterion is ranked highest (about $49 \%$ ), followed by reputation of the company (23\%), relationship with the company (15\%), availability of the product (about $8 \%$ ), and price of the product (about $6 \%$ ). From the QFD, sixteen technical requirements are prioritized and the top five technical attributes are brand image of the company (about 16.5\%), quality of raw and packaging materials (about 16.4\%), skilled production personnel (about 13\%), quality of medical representatives (about $8.5 \%$ ), and storage facility (about 7\%).

\section{Limitations and Suggestions for Future Research}

This research study has some limitations that need to be addressed. These limitations and the avenues of any possible future research are presented below.

- The present study has considered only five criteria affecting physician choice regarding pharmaceutical products. Besides these, there could be other criteria that need to be taken into account. For doing so, extensive survey can be conducted to identify more factors influencing such decisions. In this context, other research methodology like 'factor analysis' could be utilized as an extension of this paper.

- In AHP, hierarchy construction is one of the major tasks. However, the current study is confined only to addressing the ranking of the criteria in choosing pharmaceutical products. In order to get greater insight into the choice of customer, each criterion could further be divided into some sub criteria which can be taken into consideration in future research. Moreover, future research should also be extended by considering a number of possible alternatives for selecting pharmaceutical products as well as finding out how these alternatives are ranked.

- The present study did not construct the roof of the HOQ which is necessary to specify tradeoffs and appropriate design requirement. In this regard, further development could be oriented by studying the correlations between pairs of HOW. To do so, inter functional team should be set up to fill the matrix. In this regard, extensive discussion might be required between marketing manager, design manager and production manager. Discussions would help the decision makers to define the judgments about the functional characteristics as well as interpret the final ranking.

- In order to generalize the study findings, other manufacturing and service industries should be taken into account. Apart from this, in order to make the study more pragmatic, opinions of the relevant personnel from other hierarchical levels also need to be considered in future research work.

\section{References}

Alinezad, A., Seif, A., \& Esfandiari, N. (2013). Supplier Evaluation and Selection with QFD and FAHP in a Pharmaceutical Company. International Journal of Advanced Manufacturing Technology, 68, 355-364. http://dx.doi.org/10.1007/s00170-013-4733-3

Bossert, J. L. (1991). Quality Function Deployment: A Practitioner's Approach. ASQC Quality Press.

Buyukozkan, G., Feyzioglu, O., \& Ruan, D. (2007). Fuzzy group decision making to multiple preference formats in quality function deployment. Computers in Industry, 58(5), 392-402. http://dx.doi.org/10.1016/j.compind.2006.07.002

Chowdhury, P. M. (2010). An overview of the pharmaceutical sector in Bangladesh. BRAC EPL Research, 1-20.

da Cunha, U. P. (2007). Study on the viability of high quality drugs manufacturing in Bangladesh. Federal Ministry of Economic Cooperation and Development, Deutsche Gesellschaft für Technische Zusammenarbeit (GTZ) GmbH Dag-Hammarskjöld-Weg 1-5 65760 Eschborn.

De Felice, F., \& Petrillo, A. (2010). A Multiple Choice Decision Analysis: An Integrated QFD-AHP Model for the Assessment of Customer Needs. International Journal of Engineering, Science and Technology, 12(9), 25-38.

Ellison, F. S., Cockburn, I., Griliches, Z., \& Hausman, J. (1997). Characteristics of Demand for Pharmaceutical Products: An Examination of Four Cephalosporins. The RAND Journal of Economics, 28(3), 426-446. http://dx.doi.org/10.2307/2556023 
Gharakhani, D., \& Eslami, J. (2012). Determining cus-tomer needs priorities for improving service quality using QFD. International Journal of Economics and Management Sciences, 1(6), 21-28.

Gharakhani, D., \& Eslami, J. (2012). Determining customer needs priorities for improving service quality using QFD. International Journal of Economics and Management Sciences, 1(6).

Haroon, J. (2012). Local pharma market reaches $\$ 1.13$ billion. Financial Express, 20(303). Retrieved from http://www.thefinancialexpress-bd.com/more.php?news_id=121262\&date=2012-02-25.pdf

Islam, R., Ahmed, M., \& Alias, M. H. (2007). Application of Quality Function Deployment in redesigning website: a case study on TV3. International Journal of Business Information Systems, 2(2), 195-216. http://dx.doi.org/10.1504/IJBIS.2007.011619

Jain, N., \& Sing, A. R. (2014). AHP and QFD Methodology for Supplier Selection. International Proceedings of Economics Development \& Research, 75(22), 106-111.

Merrino-Castello, A. (2003). Demand for Pharmaceutical Drugs: A Choice Modeling experiment. Paper from $\mathrm{PhD}$ Dissertation. Departament d'Economia i Empresa, Universitat Pompeu Fabra, Ramon Trias Fargas, 25-27, 08005 Barcelona, Spain.

Olhager, J., \& West, B. (2002). The house of flexibility: using the QFD approach to deploy manufacturing flexibility. International Journal of Operations \& Production Management, 22(1), 50-79. http://dx.doi.org/10.1108/01443570210412079

Oliver W. (2016). What Physicians Want From Pharma in a World of Value-Based Delivery. Health \& Life Sciences. Retrieved from http://www.oliverwyman.com/insights/publications/2013/aug

Padma, P., Rajendran, C., \& Sai, L. P. (2009). A conceptual framework of service quality in healthcare: Perspectives of Indian patients and their attendants. Benchmarking: An International Journal, 16(2), 157-191. http://dx.doi.org/10.1108/14635770910948213

Rajesh, G., \& Malliga, P. (2013). Supplier selection based on AHP QFD approach. Procedia Engineering, 64, 1283-1292. http://dx.doi.org/10.1016/j.proeng.2013.09.209

Saaty, T. L. (1980). The Analytic Hierarchy Process. New York: McGraw Hill.

Sanford, J. L. (2005). How useful is QFD? Quality Progress, 38(1), 51-59.

Shamaly, S., \& Saha, S. K. (2009). Financial analysis and valuation process: using different methods to determine the actual price and its impact on current market price. Asia Pacific Business Review, 1(1).

Siddiqui, M. R., AlOthman, Z. A., \& Rahman, N. (2013). Analytical techniques in pharmaceutical analysis: A review. Arabian Journal of Chemistry. Retrieved from http://dx.doi.org/10.1016/j.arabjc.2013.04.016

Tasneem, A., Alfalah, S., \& Falah, J. (2014). The Role of Quality Function Deployment, AHP and Hierarchy Diagram in Improving Service Quality and Customer Satisfaction: An Empirical Investigation of the Jordanian Mobile Telecommunications Industry. International Journal of Core Engineering \& Management (IJCEM), 1(6).

Tendayi, T. G., \& Fourie, C. J. (2013). The Combined AHP-QFD Approach and its use in Lean Maintenance. 25th Annual South African Institute for Industrial Engineering Conference, Spier, Stellenbosch, South Africa, SAIIE 2013, 554.

Vaida, O. S., \& Kumar, S. (2006). Analytic Hierarchy Process: an overview of applications. European Journal of Operation Research, 169, 1-29. http://dx.doi.org/10.1016/j.ejor.2004.04.028

\section{Copyrights}

Copyright for this article is retained by the author, with first publication rights granted to the journal.

This is an open-access article distributed under the terms and conditions of the Creative Commons Attribution license (http://creativecommons.org/licenses/by/4.0/). 